\title{
Study of the Female Fertility of an Odd-tetraploid of Lilium and Its Potential Breeding Significance
}

\author{
Shujun Zhou ${ }^{1}$, Xin Tan, Liqin Fang, Jia Jian, Ping Xu, and Guoliang Yuan \\ Department of Horticulture, College of Agriculture and Biotechnology, Zhejiang University, No. 866 \\ of Yuhangtang Road, Hangzhou, Zhejiang Province, China
}

\begin{abstract}
Additional Index words. secondary nucleus, Fritillaria-type embryo sac, Polygonum-type embryo sac, aneuploid, megasporogenesis

ABstract. The primary objective of this research was to study the female fertility of the odd-tetraploid cultivar Honesty of Lilium containing one set of Longiflorum chromosomes and three sets of Asiatic chromosomes (LAAA) to open a new approach to Lilium breeding. To assess its female fertility, 'Honesty' was hybridized with four autotetraploid Asiatic lily cultivars. The results showed that the fruit of all 'Honesty' $\times$ tetraploid $(4 x \times 4 x)$ combinations developed well, and viable seedlings could be obtained, suggesting that 'Honesty', despite being malesterile, has considerable female fertility. Genomic in situ hybridization showed that the progenies of the $4 x \times 4 x$ hybridizations were aneuploid. Considering that lily is vegetatively propagated and aneuploids often demonstrate considerable phenotypic variation, odd-tetraploid lilies such as 'Honesty' may be useful maternal parents for breeding new lily cultivars.
\end{abstract}

Modern lily cultivars originate from hybridization of Lilium of Liliaceae. The genus contains $\approx 80$ wild species classified into seven sections: Lilium, Martagon, Pseudolirium, Archelirion, Sinomartagon, Leucolirion, and Oxypetala (De Jong, 1974). Numerous cases of interspecific hybridization suggest that intrasection compatibility is usually high, although that of intersection is very low (McRae, 1998; van Tuyl et al., 1988, 1991, 2002a, 2002b). The groups of intrasectional cultivars mainly include Asiatic (A), Longiflorum (L), Oriental (O), and Trumpet (T), and intersectional cultivars include LA hybrids, LO hybrids, and OT hybrids (van Tuyl et al., 2002a, 2002b). Intrasectional cultivars are usually diploid, whereas most intersectional cultivars are triploid (Li et al., 2011; Zhang et al., 2012). Genomic in situ hybridization (GISH) can distinguish the different genomes of intersectional lilies (Barba-Gonzalez et al., 2004; Karlov et al., 1999; Lim et al., 2000, 2003; Zhou et al., 2008a). Using GISH, we have identified a tetraploid LA cultivar that contains one L-genome and three A-genomes (LAAA) referred to as an "odd-tetraploid." Undoubtedly, the odd-tetraploid undergoes abnormal meiosis during gamete formation as a result of its genomic composition.

It is generally accepted that plants are highly sterile and seedless if they demonstrate abnormal meiotic behavior (Brandham, 1982). However, this is not the case in Lilium. Not only are there many successful $3 x \times 4 x / 2 x$ cases (BarbaGonzalez et al., 2006; Khan et al., 2009; Lim et al., 2003; Natenapit et al., 2010; Xie et al., 2010; Zhou, 2007; Zhou et al., $2011,2012)$, but also the mechanism has been interpreted (Zhou et al., 2012). The essential reason for lily triploid female fertility is that Lilium demonstrates Fritillaria-type rather than the more common Polygonum-type megasporogenesis (Maheshwari, 1948; Yadegaria and Drewsb, 2004). Because the secondary nucleus is the sum of the four daughter nuclei of the megasporocyte through meiosis in Fritillaria-type embryo

Received for publication 9 Oct. 2012. Accepted for publication 21 Dec. 2012. We thank the National Natural Science Foundation of China (31071821) for financial support. We thank Shirley Burgess for English correction.

${ }^{1}$ Corresponding author. E-mail: zhou2007@zju.edu.cn or shujunzhou@msn.com. sacs, Zhou (2007) deduced that the nuclear DNA content of the secondary nucleus in Lilium is invariably twice that of the megasporocyte regardless of whether megasporogenesis is normal or abnormal. This means the genomic composition of the secondary nucleus of any given lily is easy to ascertain. Based on numerous cases of interploid hybridization, the rule was elaborated with the new hypothesis that five identical genomes are essential for endosperm development in Lilium ("five identical genomes"). This hypothesizes that only when the endosperm from hybridization contains not less than five identical genomes will the endosperm usually develop well, and the hybridization is likely to be successful (Zhou et al., 2012). Based on pollen germination tests, 'Honesty', like with other triploid cultivars, is indeed highly male-sterile. Considering that triploid lilies, despite male sterility, can act as maternal parents in hybridization, we investigated the female fertility of 'Honesty' in hybridizations with Asiatic lilies, analyzed progenies with GISH, and discussed its potential significance on lily breeding.

\section{Materials and Methods}

Plant materials. The LA cultivar Honesty, an oddtetraploid (LAAA, $2 n=4 x=48$ ), was used as the maternal parent in controlled hybridizations with the autotetraploid (AAAA, $2 n=4 x=48$ ) Asiatic lilies 'Detroit', 'Sarina', 'Tresor', and 'Brunello' as paternal parents. All cultivars were obtained from the Hongyue Flower Co., Zhejiang Province, China, except for 'Sarina', which was obtained from the Yunnan Flower Institute, Yunnan Province, China. They were planted under natural light with regular watering in a glass greenhouse at Zhejiang University, China.

ANTHER MeIosis. Microsporogenesis was observed according to Zhou et al. (2008b). Sections of anther at anaphase II and telophase II, $1 \mathrm{~mm}$, were cut with a razor blade on a slide. One drop of 2\% acetocarmine (Fluka 22000; Sigma-Aldrich, Schweiz, Switzerland) was immediately added and gently mixed with pollen mother cells (PMCs), removing the unnecessary debris with a needle. The slide was covered with a square 
cover glass and observed under a light microscope (BH-2; Olympus, Tokyo, Japan). Images were taken with an attached charge-coupled device (CCD) camera driven with the USB2.0 Camera Application.

Pollen germination, pollination, ANd embryo rescue. The methods were according to Zhou et al. (2011). Pollen was germinated on a medium containing $100 \mathrm{~g} \cdot \mathrm{L}^{-1}$ sucrose (Sinopharm Chemical Reagent Co., Shanghai, China), $5 \mathrm{~g} \cdot \mathrm{L}^{-1}$ bacteriological agar (Sinopharm Chemical Reagent Co.), $20 \mathrm{mg} \cdot \mathrm{L}^{-1}$ boric acid (Shanghai Yunling Refinery, Shanghai, China), and $200 \mathrm{mg} \cdot \mathrm{L}^{-1} \mathrm{Ca}\left(\mathrm{NO}_{3}\right)_{2}$ (Shanghai Naihui PengzhengYingfang Refinery, Shanghai, China) and kept at $25^{\circ} \mathrm{C}$ overnight. The germinated pollen was observed under a trinocular stereomicroscope (SZM745T; Oplenic, Hangzhou, China) and images were recorded with an attached digital camera. One hundred to 150 pollen grains were counted to calculate percentage germination. Before anthesis, anthers of maternal plants were removed for hand pollination. Having been pollinated, the styles were wrapped with aluminum foil. Pollination was conducted in June 2011. Fruit were harvested for in vitro embryo rescue in a laminar air flow cabinet when they became soft or exhibited yellowing. Each fruit was sterilized using $80 \%$ ethanol (Sinopharm Chemical Reagent Co.). The seedcoats were carefully removed and the embryo sacs or embryos put on a medium $(\mathrm{pH}=5.8)$ containing $2.2 \mathrm{~g} \cdot \mathrm{L}^{-1}$ Murashige and Skoog (MS) medium (Duchefa Biochemie, Haarlem, The Netherlands), $60 \mathrm{~g} \cdot \mathrm{L}^{-1}$ sucrose, and $4 \mathrm{~g} \cdot \mathrm{L}^{-1}$ Gelrite (Duchefa Biochemie), germinated in a dark chamber at $25{ }^{\circ} \mathrm{C}$ for 40 to $60 \mathrm{~d}$, and then transferred to a medium $(\mathrm{pH}=5.8)$ containing $2.2 \mathrm{~g} \cdot \mathrm{L}^{-1} \mathrm{MS}$ medium, $50 \mathrm{~g} \cdot \mathrm{L}^{-1}$ sucrose, and $4 \mathrm{~g} \cdot \mathrm{L}^{-1}$ Gelrite at $25^{\circ} \mathrm{C}$ and kept at $2500 \mathrm{~lx}$ light intensity for $\approx 10$ weeks.

Chromosome preparation. The protocol was according to Zhou et al. (2011). When lily roots were $\approx 1 \mathrm{~cm}$ long, they were cut off and pretreated with $0.7 \mathrm{~mm}$ cycloheximide (Amresco, Solon, $\mathrm{OH}$ ), at room temperature for $4 \mathrm{~h}$, and then fixed in 3 ethanol:1 acetic acid (Sinopharm Chemical Reagent Co.) overnight. The root tips were softened with a $1 \%(\mathrm{w} / \mathrm{v})$ cellulase RS (Duchefa Biochemie) and 1\% (w/v) pectinase Y23 (Duthefa Biochemie) $\operatorname{mix}$ at $37{ }^{\circ} \mathrm{C}$ for $\approx 1 \mathrm{~h}$. The meristem was mixed with a drop of $45 \%$ acetic acid on a glass slide, covered with a glass coverslip, and squashed. Each slide was examined under a phase contrast microscope (BH-2; Olympus) for in situ hybridization.

GENOMIC IN SITU HYBRIDIZATION. The protocol was according to Zhou et al. (2012). Genomic DNA of Longiflorum 'White Fox' was isolated using the CTAB method and labeled with biotin-16-dUTP as the probe, according to the manufacturer's instructions (Biotin-Nick Translation Mix 11745824910; Roche, Mannheim, Germany). The hybridization mix $(40 \mu \mathrm{L})$ contained $50 \%$ deionized formamide, $10 \%$ dextran sulphate (0198, Amresco), 2× SSC (Saline sodium citrate buffer; $0.3 \mathrm{M}$ $\mathrm{NaCl}$ plus $30 \mathrm{~mm}$ sodium citrate, $\mathrm{pH} 7.0$ ), $0.25 \%$ sodium dodecylsulfate, 25 to $50 \mathrm{ng}$ probe DNA, and $2 \mu \mathrm{g}$ herring sperm DNA (D3159; Sigma-Aldrich). In situ hybridization was performed according to the method described by Zhou et al. (2008a). Signal was detected with Streptavidin-CY3 (Invitrogen, Camarillo, CA) and Biotinylated Anti-Streptavidin (Vector Laboratories, Burlingame, CA) according to the procedure described by Barba-Gonzalez et al. (2004). After counterstaining with diamidino phenyl indole (Roche), the slides were observed under a fluorescence microscope (BH41; Olympus). Images were taken with an attached CCD (Micropublisher 3.3
RTV; QImaging, Surrey, British Columbia, Canada) driven by Image-Pro ${ }^{\circledR}$ (MediaCybernetics, Rockville, MD). L-genome chromosomes or segments were labeled pink and A-genome ones blue or purple.

\section{Results}

Commercially, 'Honesty' is marketed as an LA hybrid. GISH analysis indicated that it contains one set of Longiflorum chromosomes $\left(\mathrm{L}^{\mathrm{ch}}\right)$ and three sets of Asiatic chromosomes $\left(\mathrm{A}^{\mathrm{ch}}\right)$ (LAAA: $2 n=4 x=12 \mathrm{~L}^{\text {ch }}+36 \mathrm{~A}^{\mathrm{ch}}$ ) without any recombinant chromosomes (Fig. 1A). Lagging chromosomes were observed in most PMCs from anaphase II to telophase II (Fig. 1B), demonstrating that 'Honesty' has abnormal microsporogenesis. Germination of fresh pollen reaches $4 \%$ but drops to zero after storage in a desiccator at room temperature for 1 week, suggesting high male sterility (Table 1).

The four Asiatic lily cultivars used as paternal parents were autotetraploid (AAAA: $2 n=4 x=48 \mathrm{~A}^{\mathrm{ch}}$ ). Their pollen germination varied from $11.5 \%$ to $54.0 \%$ (Table 1 ). When they were used as paternal parents in hybridization with 'Honesty', most fruit of all hybridizations developed well (Fig. 2) with approximately six to 27 well-developed seeds per fruit and, on average, 0.8 to 11 seedlings per fruit could be rescued in vitro from the hybridizations (Table 2). This suggests that 'Honesty', although it demonstrated abnormal meiosis and male sterility, could be used as the maternal parent in hybridizations with appropriate paternal parents.
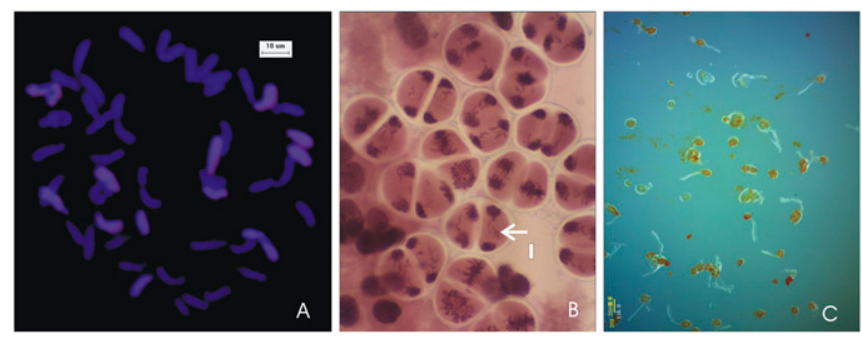

Fig. 1. (A) Lily 'Honesty' contains 12 Longiflorum chromosomes (pink) and 36 Asiatic chromosomes (purple) based on genomic in situ hybridization (GISH); bar $=10 \mu \mathrm{m}$. (B) In the odd tetraploid lily, 'Honesty', lagging chromosomes are common in pollen mother cells from anaphase II to telophase II, indicating it had abnormal meiosis. The arrow indicates examples of lagging chromosomes; bar $=20 \mu \mathrm{m}$. (C) Pollen germination status of Asiatic lily 'Detroit'; bar $=200 \mu \mathrm{m}$.

Table 1. The genome composition and pollen germination of lily cultivars used to confirm paternal and maternal parents in hybridizations. $^{z}$

\begin{tabular}{lcc}
\hline Cultivar name & Genome composition & Pollen germination (\%) \\
\hline Honesty & LAAA & $0-4$ \\
Detroit & AAAA & 45.0 \\
Sarina & AAAA & 54.0 \\
Tresor & AAAA & 11.5 \\
Brunello & AAAA & 24.5
\end{tabular}

"'Honesty' is an odd-tetraploid, containing one Longiflorum (L) genome and three Asiatic (A) genomes (i.e., LAAA). The germination was tested with fresh pollen and the pollen stored for 1 week. All the other cultivars are autotetraploid, composed of four A genomes (i.e., AAAA). Before pollination, the pollen of one flower from each cultivar was tested once for germination at $25^{\circ} \mathrm{C}$. 

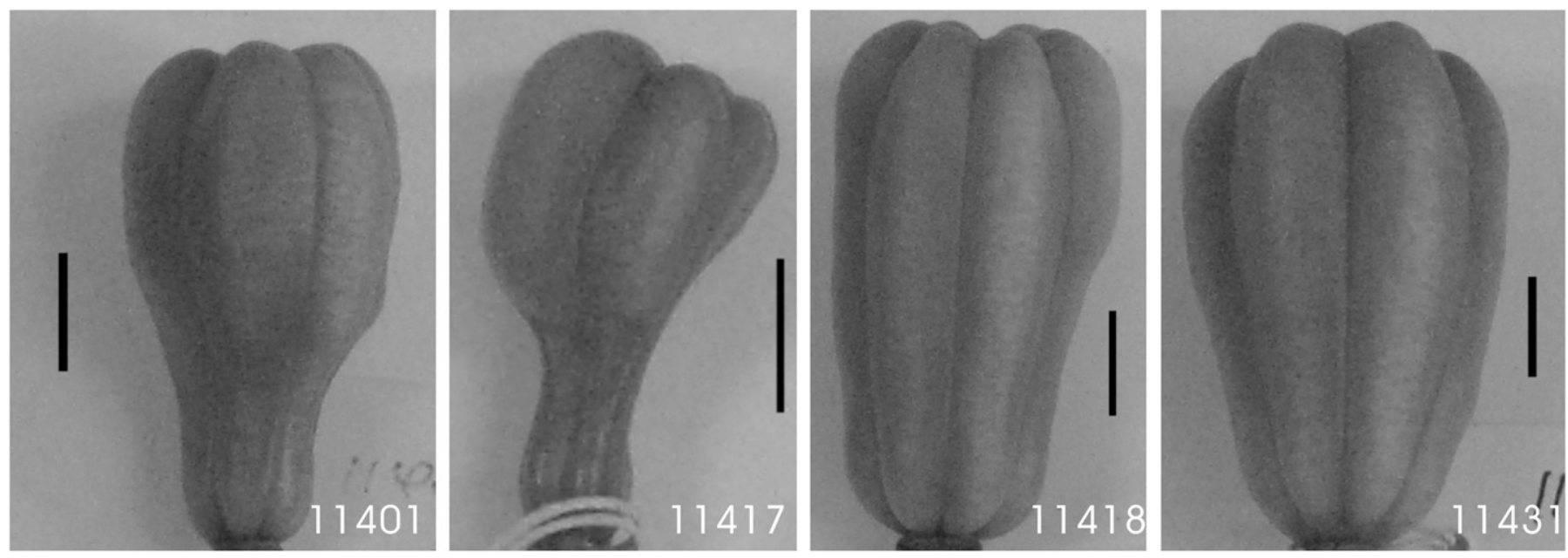

Fig. 2. Fruits of hybridizations between odd-tetraploid lily and autotetraploid lilies, at harvesting stage for embryo rescue, indicate that the fruits developed well when the odd-tetraploid 'Honesty', regardless of high male sterility, was used as the maternal parent to hybridize with the autotetraploid Asiatic lilies ('Detroit', 'Sarina', 'Tresor', and 'Bruello'). 'Honesty' contains one Longiforum (L) genome and three Asiatic (A) genomes (LAAA), and each the Asiatic lily is composed of four A genomes (AAAA); $11401=$ 'Honesty' $\times$ 'Detroit', $11417=$ 'Honesty' $\times$ 'Sarina', $11418=$ 'Honesty' $\times$ 'Tresor', $11431=$ 'Honesty' $\times$ 'Brunello'; bar $=1 \mathrm{~cm}$.

Table 2. Results of the hybridizations between the odd-tetraploid lily 'Honesty' and the autotetraploid Asiatic lilies ('Detroit', 'Sarina', 'Tresor', and 'Bruello').'

\begin{tabular}{|c|c|c|c|c|c|c|c|c|c|}
\hline Code & $\frac{\text { Cultivar ( }(\text { ) }}{\text { (LAAA) }}$ & $x$ & $\frac{\text { Cultivar }(\hat{})}{\text { (AAAA) }}$ & $\begin{array}{c}\text { Date of } \\
\text { pollination }\end{array}$ & $\begin{array}{c}\text { Flowers } \\
\text { (no.) }\end{array}$ & $\begin{array}{l}\text { Fruit } \\
\text { (no.) }\end{array}$ & $\begin{array}{c}\text { Seeds } \\
\text { (no.) }\end{array}$ & $\begin{array}{l}\text { Seedlings } \\
\text { (no.) }\end{array}$ & $\begin{array}{l}\text { Seedlings per } \\
\text { fruit (no.) }\end{array}$ \\
\hline 11401 & Honesty & & Detroit & 13 June & 11 & 5 & 42 & 4 & 0.8 \\
\hline 11417 & Honesty & & Sarina & 15 June & 10 & 8 & 202 & 79 & 9.9 \\
\hline 11431 & Honesty & & Brunello & 17 June & 28 & 26 & 690 & 286 & 11.0 \\
\hline
\end{tabular}

z'Honesty' contains one Longiforum (L) genome and three Asiatic (A) genomes (i.e., LAAA), and each Asiatic lily is composed of four A genomes (i.e., AAAA). The results indicate that 'Honesty', regardless of high male sterility resulting from abnormal meiosis, could be used as a maternal donor to hybridize with appropriate paternal parents. For example, in hybridization 11401,11 flowers of 'Honesty' were pollinated with pollen from 'Detroit' on 13 June 2011. Five fruits were harvested for embryo rescue, 42 developed seeds were isolated, and four seedlings were obtained, giving an average of 0.8 seedlings per fruit. The variation of success of different hybridizations was mainly caused by their compatibility, and the environmental factors such as climatic fluctuation at pollination may also have some impact on the variation.

Based on GISH analyses, all progenies derived from hybridizations of 'Honesty' with the four autotetraploid paternal parents were aneuploid (Fig. 3; Table 3). Chromosome numbers of the offspring varied from 42 to 70 . Because the paternal parent theoretically contributed 24 Asiatic chromosomes, 'Honesty' correspondingly contributed 18 to 46 chromosomes. Eighteen of the 21 offspring (85.7\%) resulted from the eggs with $2 x \pm 6$ chromosomes (Table 3 ). This conclusion is supported by the meiotic behavior observed from anaphase II to telophase II in PMCs (Fig. 1B). It is deduced that 'Honesty' megaspore mother cells demonstrate abnormal meiotic behavior similar to the pollen mother cells. All progeny contained a variable number of $\mathrm{L}$ chromosomes and/or L/A recombinant chromosomes, both originating from 'Honesty'. In the progeny, there were up to nine $\mathrm{L}$ chromosomes and up to five L/A chromosomes. Because all the progeny, except for 11431-25, contained some recombinant chromosomes, there must be a complex association between L and A homoeologous chromosomes at metaphase I during megasporogenesis in 'Honesty'. From the GISH analysis, it is clear that the 'Honesty' parent contributed the high level of variation through the aneuploid functional eggs.

\section{Discussion}

This is the first report that 'Honesty' can be used as the maternal parent in $4 x \times 4 x$ hybridization in Lilium. This oddtetraploid cultivar behaves similarly to triploid cultivars of Lilium: both demonstrate abnormal meiosis and produce functional aneuploid female gametes. Most triploid lilies are highly male-sterile and cannot be used as paternal parents; however, they can act as the maternal donor to hybridize with appropriate paternal parents (Barba-Gonzalez et al., 2006; Khan et al., 2009; Lim et al., 2003; Xie et al., 2010; Zhou, 2007; Zhou et al., 2011, 2012). The similar behavior of 'Honesty' and triploid cultivars could be explained by the same mechanism. Because Lilium demonstrate Fritillaria-type megasporogenesis (Maheshwari, 1948; Yadegaria and Drewsb, 2004), Zhou (2007) deduced that the amount of nuclear DNA of the secondary nucleus is invariably twice that of its megasporocyte, regardless of whether meiosis is normal or abnormal. This clearly explains the difference in fruit development between reciprocal crosses in Lilium. Based on further analysis of $3 x \times 2 x / 4 x$ lily hybridizations, Zhou et al. (2012) proposed the "five identical genomes" hypothesis to explain 


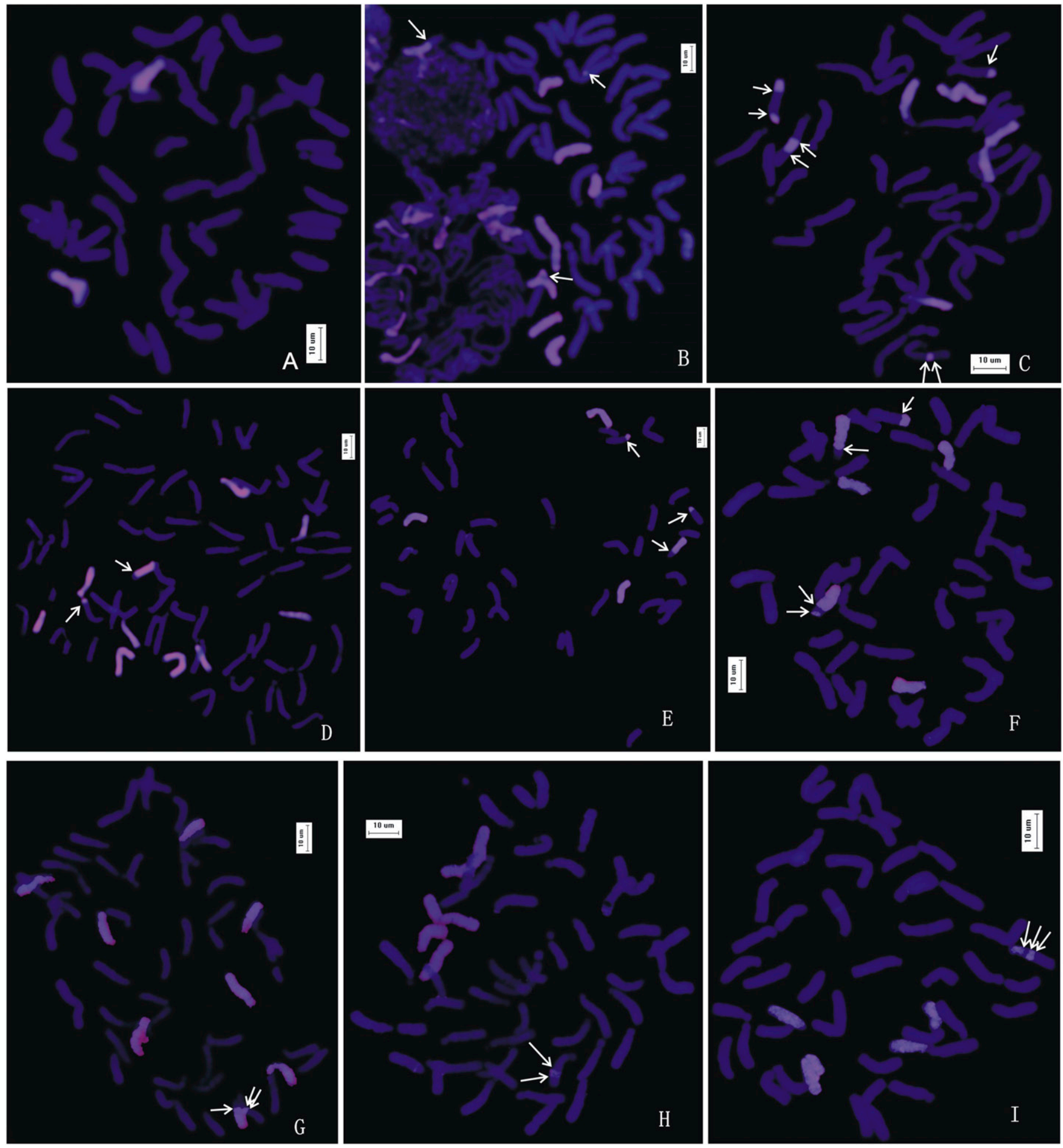

Fig. 3. The chromosomes at metaphase of representative progenies of lily hybridization 11431 ('Honesty' $\times$ 'Brunello') were stained with genomic in situ hybridization (GISH). The results indicated that they had various Longiflorum (L) and Asiatic (A) chromosomes. The pink chromosomes or segments belong to the $\mathrm{L}$ genome $\left(\mathrm{L}^{\mathrm{ch}}\right)$, whereas those stained blue or purple belong to the A genome $\left(\mathrm{A}^{\mathrm{ch}}\right)$. Arrows indicate the recombination point; bar $=10 \mu \mathrm{m} .(\mathbf{A}) 11431-25(2 n=$ $\left.2 \mathrm{~L}^{\text {ch }}+43 \mathrm{~A}^{\text {ch }}\right),($ B $) 11431-27\left(2 n=7 \mathrm{~L}^{\text {ch }}+46 \mathrm{~A}^{\text {ch }}+3 \mathrm{~L} / \mathrm{A}^{\text {ch }}\right),(\mathbf{C}) 11431-44\left(2 n=4 \mathrm{~L}^{\text {ch }}+36 \mathrm{~A}^{\text {ch }}+4 \mathrm{~L} / \mathrm{A}^{\text {ch }}\right),(\mathbf{D}) 11431-47\left(2 n=9 \mathrm{~L}^{\mathrm{ch}}+59 \mathrm{~A}^{\mathrm{ch}}+2 \mathrm{~L} / \mathrm{A}^{\mathrm{ch}}\right),(\mathbf{E}) 11431-54$ $\left(2 n=3 \mathrm{~L}^{\mathrm{ch}}+42 \mathrm{~A}^{\mathrm{ch}}+3 \mathrm{~L} / \mathrm{A}^{\mathrm{ch}}\right),(\mathbf{F}) 11431-78\left(2 n=3 \mathrm{~L}^{\mathrm{ch}}+36 \mathrm{~A}^{\mathrm{ch}}+3 \mathrm{~L} / \mathrm{A}^{\mathrm{ch}}\right),(\mathbf{G}) 11431-85\left(2 n=7 \mathrm{~L}^{\mathrm{ch}}+38 \mathrm{~A}^{\mathrm{ch}}+2 \mathrm{~L} / \mathrm{A}^{\mathrm{ch}}\right),(\mathbf{H}) 11431-86\left(2 n=4 \mathrm{~L}^{\mathrm{ch}}+43 \mathrm{~A}^{\mathrm{ch}}+1 \mathrm{~L} / \mathrm{A}^{\mathrm{ch}}\right)$, (I) $11431-100\left(2 n=4 \mathrm{~L}^{\text {ch }}+40 \mathrm{~A}^{\text {ch }}+1 \mathrm{~L} / \mathrm{A}^{\text {ch }}\right)$.

why such interploid hybridizations are successful. The hybridizations between 'Honesty' and the autotetraploid Asiatic cultivars (LAAA $\times$ AAAA) in the present research can be similarly interpreted. Because of abnormal meiosis during megasporogenesis, 'Honesty' (LAAA) usually produces an aneuploid egg but an octaploid secondary nucleus $(8 x=2 \mathrm{~L}+$ $6 \mathrm{~A}$ ) in its embryo sac, and the Asiatic cultivars (AAAA) produce diploid pollen $(2 x=2 \mathrm{~A})$. After double fertilization, 
Table 3. Variation in chromosome number of different progenies obtained from the hybridization between lilies 'Honesty' and 'Brunello'.

\begin{tabular}{lcccccc}
\hline Code & $\begin{array}{c}\text { Chromosome } \\
\text { no. }\end{array}$ & $\begin{array}{c}\mathrm{L}^{\text {ch }} \\
\text { (no.) }\end{array}$ & $\begin{array}{c}\mathrm{A}^{\text {ch }} \\
\text { (no.) }\end{array}$ & $\begin{array}{c}\mathrm{L}^{\text {c }} \text { ch } \\
\text { (no.) }\end{array}$ & $\begin{array}{c}\text { Pollen }^{\text {ch }} \\
\text { (no.) }\end{array}$ & $\begin{array}{c}\text { Egg }^{\text {ch }} \\
\text { (no.) }\end{array}$ \\
\hline $11431-03$ & 45 & 2 & 39 & 4 & 24 & 21 \\
$11431-07$ & 48 & 6 & 39 & 3 & 24 & 24 \\
$11431-17$ & 47 & 4 & 39 & 4 & 24 & 23 \\
$11431-22$ & 42 & 5 & 35 & 2 & 24 & 18 \\
$11431-25$ & 45 & 2 & 43 & 0 & 24 & 21 \\
$11431-27$ & 56 & 7 & 46 & 3 & 24 & 32 \\
$11431-35$ & 51 & 3 & 43 & 5 & 24 & 27 \\
$11431-40$ & 70 & 5 & 62 & 3 & 24 & 46 \\
$11431-44$ & 44 & 4 & 36 & 4 & 24 & 20 \\
$11431-47$ & 70 & 9 & 59 & 2 & 24 & 46 \\
$11431-48$ & 47 & 3 & 40 & 4 & 24 & 23 \\
$11431-51$ & 48 & 0 & 43 & 5 & 24 & 24 \\
$11431-54$ & 48 & 3 & 42 & 3 & 24 & 24 \\
$11431-55$ & 51 & 8 & 41 & 2 & 24 & 27 \\
$11431-62$ & 49 & 5 & 42 & 2 & 24 & 25 \\
$11431-78$ & 42 & 3 & 36 & 3 & 24 & 18 \\
$11431-85$ & 47 & 7 & 38 & 2 & 24 & 23 \\
$11431-86$ & 48 & 4 & 43 & 1 & 24 & 24 \\
$11431-88$ & 43 & 1 & 39 & 3 & 24 & 19 \\
$11431-100$ & 45 & 4 & 40 & 1 & 24 & 21 \\
\hline
\end{tabular}

${ }^{\mathrm{z}}$ For example, progeny 11431-03 had 45 chromosomes, two of which were Longiflorum chromosomes $\left(\mathrm{L}^{\mathrm{ch}}\right), 39$ Asiatic chromosomes $\left(\mathrm{A}^{\mathrm{ch}}\right)$, and four recombinant chromosomes $\left(\mathrm{L} / \mathrm{A}^{\mathrm{ch}}\right)$. For chromosomal origin, 24 were contributed by pollen (Pollen ${ }^{\text {ch }}$ ) of 'Brunello' and 21 by egg $\left(\mathrm{Egg}^{\mathrm{ch}}\right)$ of 'Honesty'. The variation in chromosome number of the progenies was caused by the difference in the eggs of 'Honesty' as a result of abnormal meiosis.

the embryo is usually aneuploid but the endosperm is invariably euploid $(10 x=2 \mathrm{~L}+8 \mathrm{~A})$. According to the "five identical genomes" hypothesis, the endosperm could develop and result in the survival of aneuploid embryos. The present result is a further example that supports the "five identical genomes" hypothesis.

There are many factors influencing hybridization success or failure. It is reasonable that, in Lilium, hybridizations with "five identical genomes" are likely to produce some seeds with functional endosperm, the nourishing tissue for embryo development, making the hybridizations successful. However, hybridizations without "five identical genomes" are not impossible (Zhou et al., 2012). For example, the endosperm of $\mathrm{LL} \times \mathrm{AA}$ and $\mathrm{LA} \times \mathrm{AA}$ is ' $4 \mathrm{~L}+\mathrm{A}$ ' and ' $2 \mathrm{~L}+3 \mathrm{~A}$ ', respectively. When LL $\times$ AA and LA $\times$ AA (Zhou, 2007) crosses are compared with LAA $\times$ AA/AAAA (Zhou et al., 2012) or LAAA $\times$ AAAA of the present research, there is a marked difference between their endosperms. The developed seeds of $L L \times A A$ and LA $\times$ AA crosses are usually plump with liquid inside the ovules, whereas those of LAA $\times$ AA/AAAA or LAAA $\times$ AAAA are near normal. This suggests that the endosperm of LAA $\times$ $\mathrm{AA} / \mathrm{AAAA}$ or LAAA $\times$ AAAA (five or more identical genomes) develop better than that of $\mathrm{LL} \times \mathrm{AA}$ and $\mathrm{LA} \times \mathrm{AA}$ (less than five identical genomes). Another example is LLO $\times$ AA reported by Natenapit et al. (2010). This endosperm is $4 \mathrm{~L}+$ $2 \mathrm{O}+\mathrm{A}$, and, using ovary culture, $10 / 11$ seedlings were obtained from 6564/6585 ovules, implying that the endosperm developed poorly. This lack of success can be explained because the maternal (LLO) and paternal parent (AA) share no common genome. Hybridization with "five identical genomes" is also rarely successful if the maternal and paternal parents share no common genome; e.g., $\mathrm{AAA} \times \mathrm{LL}$ and $\mathrm{AAA} \times \mathrm{OO}$ (data not shown). Therefore, compatibility is a vital factor in crossability.

There are other plants such as tulip, which have Fritillariatype embryo sacs. Theoretically, it is expected that triploid and odd-tetraploid tulip cultivars would exhibit similar behavior in hybridizations. However, Mizuochi et al. (2009) have reported that the ratio of embryo and endosperm ploidy level of $2 x \times 2 x$ or $3 x \times 2 x$ is invariably $1: 1$, suggesting that the endosperm does not result from fusion of a sperm and a secondary nucleus. This indicates that the "five identical genomes" theory does not explain the hybridization behavior in tulip although it is also a Fritillaria-type plant.

Most plants have Polygonum-type embryo sacs (Maheshwari, 1948; Yadegaria and Drewsb, 2004). Hybridizations involving odd-tetraploid parents in Polygonum-type plants have not been reported to date. However, many $3 x \times 2 x / 4 x$ or reciprocal crosses have been reported (Ramanna and Jacobsen, 2003). Although triploids such as watermelon (Citrullus) and banana (Musa) are highly sterile and typically seedless, a few seeds are occasionally recovered. Those from $3 x \times 2 x$ are usually diploid or nearly so, whereas those from $3 x \times 4 x$ are tetraploid or nearly so, or occasionally even pentaploid (Brandham, 1982; Carputo and Barone, 2005; Carputo et al., 1999; Ramsey and Schemske, 1998, 2002). Reasons for success or failure of these interploid crosses in Polygonum-type plants include the ratio (two to one) of maternal/paternal ploidy levels of endosperm or endosperm balance number (Brandham, 1982; Carputo and Barone, 2005; Carputo et al., 1999; Johnston and Hanneman, 1982; Johnston et al., 1980), the genome composition of the endosperm itself (Dowrick and Brandram, 1970), and the effect of differential gene dosage (genome imprinting) (Dikes and Comai, 2004; Gutierrez-Marcos et al., 2003; Scott et al., 1998). From the present research, we consider that genome composition of the endosperm itself is more important for its development than the ratio of maternal/paternal ploidy levels of endosperm or endosperm balance number in Lilium.

\section{Concluding Remarks}

Lilium is an unusual kind of plant because of its Fritillariatype embryo sac. Based on the present results showing that the cultivar Honesty can function successfully as the maternal parent and produce aneuploid functional eggs, odd-tetraploid lilies can be an excellent source for lily introgression breeding, offering a new approach to lily breeding strategy.

\section{Literature Cited}

Barba-Gonzalez, R., B.H. Lokker, K.B. Lim, M.S. Ramanna, and J.M. van Tuyl. 2004. Use of $2 n$ gametes for the production of sexual polyploids from sterile Oriental $\times$ Asiatic hybrids of lilies (Lilium). Theor. Appl. Genet. 109:1125-1132.

Barba-Gonzalez, R., R.A.A. van Silfhout, M.S. Ramanna, R.G.F. Visser, and J.M. van Tuyl. 2006. Progenies of allotriploids of Oriental $\times$ Asiatic lilies (Lilium) examined by GISH analysis. Euphytica 151:243-250.

Brandham, P.E. 1982. Inter-embryo competition in the progeny of autotriploid Aloineae (Liliaceae). Genetica 59:29-42.

Carputo, D. and A. Barone. 2005. Ploidy level manipulations in potato through sexual hybridization. Ann. Appl. Biol. 146:71-79. 
Carputo, D., L. Monti, J.E. Werner, and L. Frusciante. 1999. Uses and usefulness of endosperm balance number. Theor. Appl. Genet. 98:478-484.

De Jong, P.C. 1974. Some notes on the evolution of lilies. Lily Yrbk. North Amer. Lily Soc. 27:23-28.

Dikes, B.P. and L. Comai. 2004. A differential dosage hypothesis for parental effects in seed development. Plant Cell 16:3174-3180.

Dowrick, G.J. and S. Brandram. 1970. Abnormalities of endosperm development in Lilium hybrids. Euphytica 19:433-442.

Gutierrez-Marcos, J.F., P.D. Pennington, L.M. Costa, and H.G. Dickinson. 2003. Imprinting in the endosperm: A possible role in preventing wide hybridization. Philos. Trans. R. Soc. Lond. B Biol. Sci. 358:1105-1111.

Johnston, S.A. and R.E. Hanneman, Jr. 1982. Manipulations of endosperm balance number overcome crossing barriers between diploid species. Science 217:446-448.

Johnston, S.A., T.M. den Nijs, S.J. Peloquin, and R.E. Hanneman, Jr. 1980. The significance of genic balance to endosperm development in interspecific crosses. Theor. Appl. Genet. 57:5-9.

Karlov, G.I., L.I. Khrustaleva, K.B. Lim, and J.M. van Tuyl. 1999. Homoeologous recombination in 2 n-gamete producing interspecific hybrids of Lilium (Liliaceae) studied by genomic in situ hybridization (GISH). Genome 42:681-686.

Khan, N., S. Zhou, M.S. Ramanna, P. Arens, J. Herrera, R.G.F. Visser, and J.M. van Tuyl. 2009. Potential for analytic breeding in allopolyploids: An illustration from Longiforum $\times$ Asiatic hybrid lilies (Lilium). Euphytica 166:399-409.

Li, K., G. Zhou, G. Ren, X. Zhang, F. Guo, and S. Zhou. 2011. Observation on ploidy levels of lily cultivars. Acta Hort. Sinica 38:970-976.

Lim, K.B., J.D. Chung, B.C.E. van Kronenburg, M.S. Ramanna, J.H. De Jong, and J.M. van Tuyl. 2000. Introgression of Lilium rubellum Baker chromosomes into L. Longiflorum Thunb.: A genome painting study of the $\mathrm{F}_{1}$ hybrid, $\mathrm{BC}_{1}$ and $\mathrm{BC}_{2}$ progenies. Chromosome Res. $8: 119-125$

Lim, K.B., M.S. Ramanna, J.H. De Jong, E. Jacobsen, and J.M. van Tuyl. 2003. Evaluation of $\mathrm{BC}_{2}$ progenies derived from $3 x \times 2 x$ and $3 x \times 4 x$ crosses of Lilium hybrids: A GISH analysis. Theor. Appl. Genet. 106:568-574.

Maheshwari, P. 1948. The angiosperm embryo sac. Bot. Rev. 14:1-56. McRae, E.A. 1998. Lilies: A guide for growers and collectors. Timber Press, Portland, OR.

Mizuochi, H., H. Matsuzaki, T. Moue, and K. Okazaki. 2009. Diploid endosperm formation in Tulipa spp. and identification of a 1:1 maternal-to-paternal genome ratio in endosperms of $T$. gesneriana $\mathrm{L}$. Sex. Plant Reprod. 22:27-36.

Natenapit, J., S. Taketa, T. Narumi, and S. Fukai. 2010. Crossing of the allotriploid LLO hybrid and Asiatic lilies (Lilium). Hort. Environ. Biotechnol. 51:426-430.
Ramanna, M.S. and E. Jacobsen. 2003. Relevance of sexual polyploidization for crop improvement-A review. Euphytica 133:3-18.

Ramsey, J. and D.W. Schemske. 1998. Pathways, mechanisms, and rates of polyploidy formation in flowering plants. Annu. Rev. Ecol. Syst. 29:467-501.

Ramsey, J. and D.W. Schemske. 2002. Neopolyploidy in flowering plants. Annu. Rev. Ecol. Syst. 33:589-639.

Scott, R.J., M. Spielman, J. Bailey, and H.G. Dickinson. 1998. Parentof-origin effects on seed development in Arabidopsis thaliana. Development 125:3329-3341.

van Tuyl, J.M., M.P. van Diën, M.G.M. van Creij, T.C.M. van Kleinwee, J. Franken, and R.J. Bino. 1991. Application of in vitro pollination, ovary culture, ovule culture and embryo rescue for overcoming incongruity barriers in interspecific Lilium crosses. Plant Sci. 74:115-126.

van Tuyl, J.M., C.J. Keijzer, H.J. Wilms, and A.A.M. Kwakkenbos. 1988. Interspecific hybridization between Lilium longiflorum and the white Asiatic hybrid 'Mont Blanc'. Lily Yrbk. North Amer. Lily Soc. 41:103-111.

van Tuyl, J.M., K.B. Lim, and M.S. Ramanna. 2002a. Interspecific hybridization and introgression, p. 85-103. In: Vainstein, A. (ed.). Breeding for ornamentals: Classical and molecular approaches. Kluwer Academic Publishers, Dordrecht, The Netherlands.

van Tuyl, J.M., I.W.G.M. Maas, and K.B. Lim. 2002b. Introgression in interspecific hybrids of lily. Acta Hort. 570:213-218.

Xie, S., M.S. Ramanna, and J.M. van Tuyl. 2010. Simultaneous identification of three different genomes in Lilium hybrids through multicolour GISH. Acta Hort. 855:299-303.

Yadegaria, R. and G.N. Drewsb. 2004. Female gametophyte development. Plant Cell 16:S133-S141.

Zhang, X., G. Ren, K. Li, G. Zhou, and S. Zhou. 2012. Genomic variation of new cultivars selected from distant hybridization in Lilium. Plant Breed. 131:227-230.

Zhou, S. 2007. Intergenomic recombination and introgression breeding in Longiflorum $\times$ Asiatic lilies (Lilium). $\mathrm{PhD}$ diss., Wageningen Univ., Wageningen, The Netherlands.

Zhou, S., K. Li, and G. Zhou. 2012. Analysis of endosperm development of allotriploid $\times$ diploid/tetraploid crosses in Lilium. Euphytica 184:401-412.

Zhou, S., M.S. Ramanna, R.G.F. Visser, and J.M. van Tuyl. 2008a. Genome composition of triploid lily cultivars derived from sexual polyploidization of Longiflorum $\times$ Asiatic hybrids (Lilium). Euphytica 160:207-215.

Zhou, S., M.S. Ramanna, R.G.F. Visser, and J.M. van Tuyl. 2008b. Analysis of the meiosis in the $F_{1}$ hybrids of Longiflorum $\times$ Asiatic (LA) of lilies (Lilium) using genomic in situ hybridization. J. Genet. Genomics 35:687-695.

Zhou, S., G. Zhou, and K. Li. 2011. Euploid endosperm of triploid $\times$ diploid/tetraploid crosses results in aneuploid embryo survival in Lilium. HortScience 46:558-562. 